Article

\title{
Experimental Evaluation of Aging Indicators for Lithium-Iron-Phosphate Cells
}

\author{
Massimo Ceraolo, Giovanni Lutzemberger (D), Davide Poli (D) and Claudio Scarpelli * \\ Department of Energy, Systems, Territory and Constructions Engineering, University of Pisa, 56122 Pisa, Italy; \\ massimo.ceraolo@unipi.it (M.C.); giovanni.lutzemberger@unipi.it (G.L.); davide.poli@unipi.it (D.P.) \\ * Correspondence: claudio.scarpelli@phd.unipi.it; Tel.: +39-050-2217-300
}

Citation: Ceraolo, M.; Lutzemberger, G.; Poli, D.; Scarpelli, C. Experimental Evaluation of Aging Indicators for Lithium-Iron-Phosphate Cells. Energies 2021, 14, 4813. https:// doi.org/10.3390/en14164813

Academic Editor: Teuvo Suntio

Received: 6 July 2021

Accepted: 5 August 2021

Published: 7 August 2021

Publisher's Note: MDPI stays neutral with regard to jurisdictional claims in published maps and institutional affiliations.

Copyright: (c) 2021 by the authors. Licensee MDPI, Basel, Switzerland. This article is an open access article distributed under the terms and conditions of the Creative Commons Attribution (CC BY) license (https:// creativecommons.org/licenses/by/ $4.0 /)$.

\begin{abstract}
Degradation mechanism of batteries has to be carefully studied when considering their utilization in electrical power systems. This paper presents the results of an extensive experimental campaign, through which three different lithium-iron-phosphate (LFP) cells were subjected to different electrical cycling stresses. The purpose of the campaign was to evaluate the cells' aging, as well as to try to find parameters on the cell behavior before its end of life, able to act as state-of-life (SOL) (or aging) indicators. The considered stress consists of the cyclic repetition of fixed-duration discharge steps, followed by full charge phases. The three cells under study were subjected to the very same stress pattern but with three different discharge and charge power levels: low, medium, and high. The results showed that the end-of-discharge voltage and the cell internal resistance can be used as good SOL indicators. However, both are significant functions of the cell conditions, such as the state of charge (SOC) and the cell temperature.
\end{abstract}

Keywords: aging; experimental; lithium; parameters; testing

\section{Introduction}

Lithium-based cells and batteries have become a de facto standard for many storage applications, either stationary or vehicular. Among the several available chemistries, lithium-iron-phosphate (LFP) cells are appreciated for their very good stability, low cost, reasonable specific energy, and energy densities, even though these densities are somewhat lower than other chemistries [1,2]. Lithium cells guarantee rather large number of cycles, in most cases a few thousands for stationary applications [1], around one thousand for vehicles [1]. However, it is well known that the cycle life depends on the cell utilization, typically increasing, in terms of the whole energy delivered throughout the cell's life, when the usage involves shallower cycles [3]. The strong dependence of aging on the usage pattern makes it very difficult to predict it on the basis of a cell's aging model alone, although good attempts in this direction have been made [4-6]. This paper takes a different approach: it tried to find, on the basis of experimental results, indicators of cell aging that could be used during a cell's life to evaluate the so-called state of life (SOL), i.e., the nearness of the cell itself to its end of life. For this, a good opportunity for the authors was the SUMA project to which the department to which they belong participates. One of the goals of this project is to evaluate several aspects of electric vehicle charging in multifunctional structures (called SUMA themselves), which have some renewable generation (e.g., solar panels), electric vehicle supply equipment (EVSE) units, and electrochemical storage. In these structures, electrochemical storage has two purposes:

- Compensating the power fluctuation of the renewable source;

- Compensating the peak powers occurring at the first intervals of vehicle charging operations.

For the first purpose, an energy-oriented storage system is needed; for the second purpose, a power-oriented storage system is required. Although both purposes can be 
pursued with just one cell design using a well-designed battery, SUMA chose to consider in the installation of different storage systems, one for energy, the other for power services. To deliver power services, the chosen cell was an LFP one; this choice led to specific experimental tests to try to find aging indicators, or indicators of the so-called state-of-life (SOL), as well as to evaluate the cell's cycle life under specified conditions, calibrated for the SUMA project [7]. A first paper on this was presented in [8], in which experimental tests were limited only to two cells; therefore, the analysis was performed on the basis of limited data only. This paper presents a more complete and comprehensive analysis. In particular, a third cell was added in order to increase the data to be analyzed, and to make a more complete analysis regarding the correlation between internal resistance and aging, which provided several interpretation issues in [8]. The extended approach and new data allow the paper to overcome the previous limits, as well as to evaluate which indicators, among the ones selected, can be used to make more precise cell aging evaluation.

\section{The Test Procedure and Experimental Set-Up}

\subsection{The Reference Discharge Chosen}

Inside the SUMA project, the purpose of the tested cells is to provide power services in order to compensate the peak power during relatively fast charge of vehicles. SUMA multifunctional structures are to be installed inside urban contexts, where on one hand space occupation must be limited, and on the other hand customers need only a relatively small recharge, simply to gain additional range for the remainder of the trip. Therefore, 15 min was chosen for the discharge duration. The actual $\mathrm{kW}$ and $\mathrm{kWh}$ size of the battery will depend on the SUMA size, in accordance with the number of cells contained in the battery pack, while the 15 min requirement was decided to be taken fixed. Moreover, to be nearer to real usage profiles, instead of using the more common constant-current charging/discharging profile, we chose constant power.

\subsection{The Cycle-life Test Pattern}

Since life tests last long period of time, typically months, an industrial device is needed in order to automate the test process, as well as to allow tests to be performed, without interruption, for several days or weeks. The considered test is shown in Figure 1a, and, as discussed earlier, is inspired by the common needs of an electric vehicle when charged for about $15 \mathrm{~min}$ [8]. All the aging tests are performed on single cells; therefore, the final results will also refer to the aging phenomena at the cell level.

Good information on the cell aging phenomenon is very important to infer; at a later stage of analysis, information of the aging of whole battery packs can be obtained.

Battery packs are, nearly always, equipped with sensors of all cell voltages and several temperatures (from which, using thermal models of the packs, individual cell temperatures can be evaluated). In this way, the results of this paper can be applied, with the obvious complication of having to run the pack thermal model, rather straightforwardly to packs. This leads to the issue of inhomogeneity of SOL of cells inside the same pack, as well as possible countermeasures, which are, however, out of the scope of this paper.

The test is composed of many cycling periods interspersed with cell characterization phases (CCPs). The cycling pattern, shown in Figure 1b, starts with a constant-power discharging followed by a constant-power charging, which ends when voltage reaches the maximum value allowed by the manufacturer of the cell (i.e., $4 \mathrm{~V}$ ). The third phase is a pause (zero current). Charging and discharging phases are performed using the same power. The cell characterization phase (Figure 1c) consists of a $30 \mathrm{~A}(0.5 \mathrm{C})$ constant current discharge (end-of-discharge voltage $2.8 \mathrm{~V}$ ) and a subsequent constant current-constant voltage charging performed at same $0.5 \mathrm{C}$ (end-of-charge voltage $4.0 \mathrm{~V}$ ), followed by a $2 \mathrm{~h}$ pause. The aging indicators, monitored and analyzed in terms of the function of the number of executed cycles, are as follows:

- $\quad$ The cell available capacity $C_{a, n}$; measured during the nth CCP; 
- The cell internal resistances evaluated during the cycling periods, at the beginning and at the end of each discharge;

- The cell case temperature, always measured;

- The end-of-discharge voltage reached $V_{\mathrm{EOD}, \mathrm{n}}$ measured during the cycling periods at the end of every discharge.

(a) Aging test

\begin{tabular}{|l|l|l|l|}
\hline CCP & Cycling period & CCP & Cycling period
\end{tabular}$\ldots$

(b) Cycling period (one cycle shown, cell250)
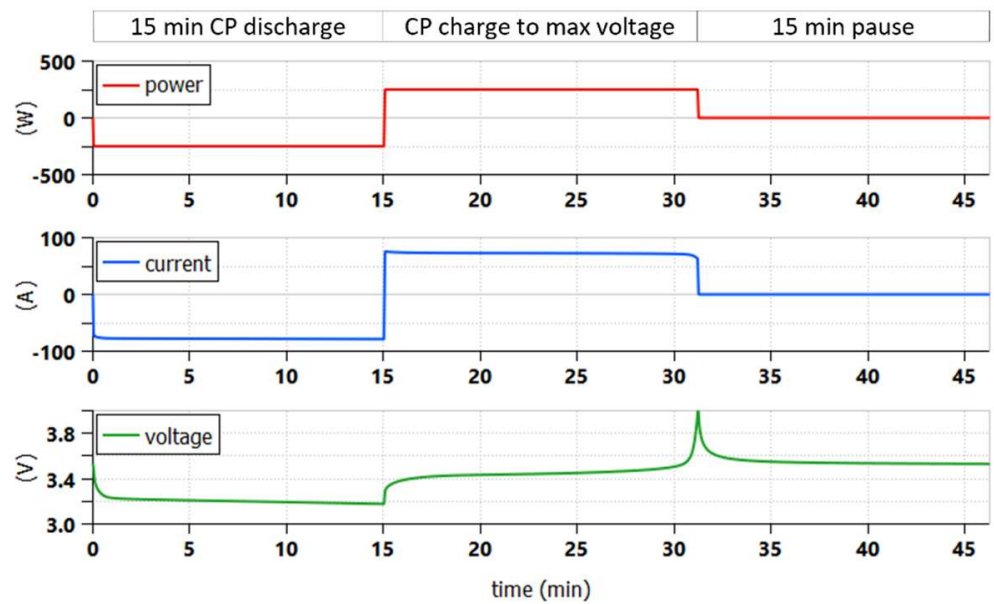

(c) Cell characterization phase (CCP)
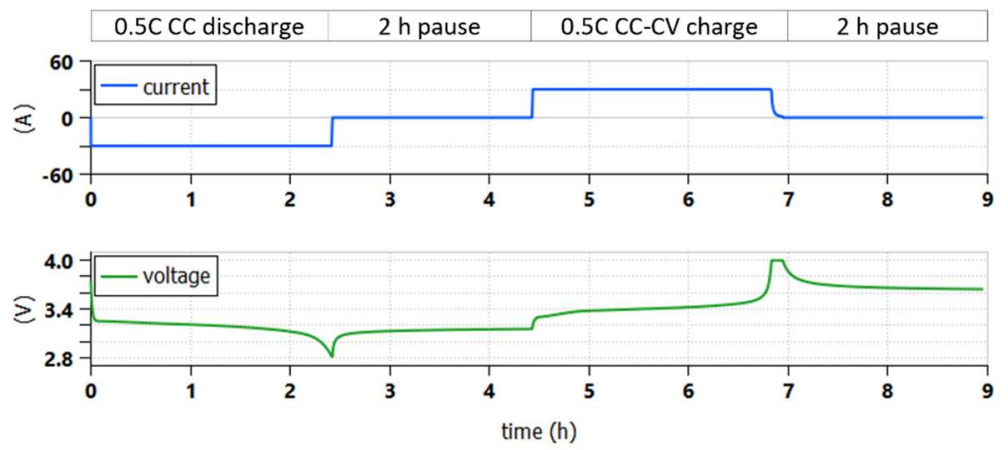

Figure 1. (a) Aging test structure: cycling periods interspersed with cell characterization phases (CCP). (b) Cycling period patterns: one single cycle shown, cell250 power, voltage, and current. (c) Cell characterization phase current and voltage.

The above-described test was applied to three identical cells, called cell250 cell375, and cell500, which were cycled at constant power equal to $250 \mathrm{~W}, 375 \mathrm{~W}$, and $500 \mathrm{~W}$, respectively. The $500 \mathrm{~W}$ level implies charge and discharge currents closer to the maximum admitted value of $180 \mathrm{~A}$ (3C) - this was chosen to determine the cell cycle life corresponding to the maximum realistic power usage pattern. The aging test was continued up to when the minimum voltage during the discharge phase reached the minimum allowed by the manufacturer. For the cells here tested, this value was set to $2.5 \mathrm{~V}$ (as will be displayed in Section 2.2, Table 1), but we decided to raise this threshold to $2.65 \mathrm{~V}$ for security reasons. This end-of-discharge condition was chosen because throughout the life test, the battery is subject to constant-duration discharges, which implies only partial discharges occur, which in turn implies the voltage will always stay above $2.65 \mathrm{~V}$, except when, because of the reduced capacity due to aging, this threshold is reached. 
Table 1. LFP lithium cell characteristics.

\begin{tabular}{cc}
\hline Manufacturer & Winston Battery \\
Model name & WB-LYP060AHA \\
Chemistry & LFP \\
Nominal capacity (Ah) & 60 \\
Nominal voltage (V) & 3.2 \\
Operating voltage (V) & max 4.0-min 2.8 \\
Deep discharge voltage (V) & 2.5 (damage if below) \\
Optimal discharge current (A) & 30 \\
Max discharge current (A) & 180 \\
Max peak discharge current (A) & $600(5 \mathrm{~s} \mathrm{max})$ \\
Optimal charge current (A) & 30 \\
Max charge current (A) & 180 \\
Max operating temperature $\left({ }^{\circ} \mathrm{C}\right)$ & 80 \\
Dimension $(\mathrm{mm})$ & $114 \times 203 \times 61$ \\
Weight $(\mathrm{kg})$ & 2.3 \\
\hline
\end{tabular}

\subsection{Experimental Setup}

The test setup was composed of a charging and discharging system driven by a Digatron ${ }^{\circledR}$ battery cell tester and two thermostatic chambers, wherein the cells under testing were positioned, whose main characteristics are reported in Table A1 in the Appendix A [8-10]. A picture of the experimental setup inside the climatic chamber is found in Figure 2, while a picture of the laboratory is shown in Figure A1. In particular, it shows that the cells temperature was obtained by a thermocouple in close contact with the cell's surface. During all tests, the surface cell temperature was continuously monitored, as well as the thermostatic chamber temperature, measured very far from the cell by the built-in chamber sensor.

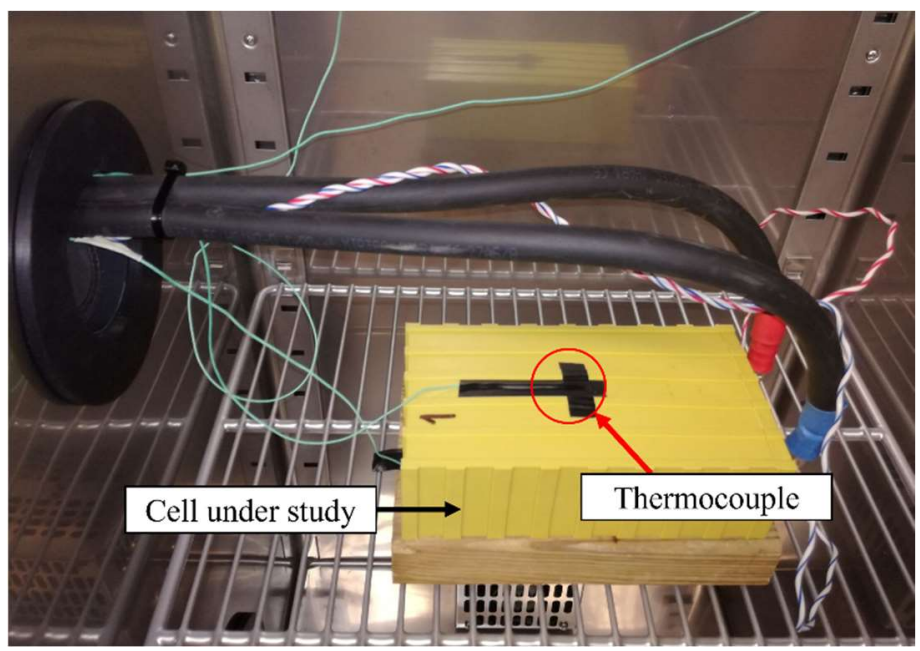

Figure 2. Picture of the cell under test inside the climatic chamber.

\subsection{Device under Test}

The three LFP lithium cells tested were made by Winston Battery [11]; their datasheet is summarized in Table 1.

\section{Aging Indicators}

This paragraph shows how the four aging indicators are defined and evaluated through the aging test described in Figure 1 for each cell, as a in function of the number of cycles performed. 


\subsection{Available Capacity}

The available capacity is defined as the charge extracted during the constant current discharging phase of each CCP (see Figure 1). This capacity can be expressed in Ah or as a ratio to the beginning-of-life capacity:

$$
C_{p u}=\frac{C_{a}}{C_{B O L}}
$$

This indicator is rather obvious, as it is well known that the clearest aging indicator is the reduction in the capacity the battery can deliver. However, in real-life applications, measuring the discharge capacity often requires conducting ad hoc tests, which have the disadvantage of interrupting the ordinary activity of the cell, and might imply requiring special hardware to be provided for in order to perform this constant-current discharge. Because of this, additional indicators are searched, which would in principle allow evaluation of the aging, i.e., the state-of-life (SOL) of the battery, while the battery is performing its business-as-usual operation.

\subsection{Heat Generation}

It is a common experience that, a far as cells age, their internal resistance increases, and because of this, the heat generation also increases. This was also observed during the tests reported in this paper. If the heat generation is sufficiently high, this can result in an increased overtemperature of the battery in comparison with its surrounding air. This could be easily measured real time in real-life applications. Thus, as an indicator of the cell internal heat generation, in our test, we measured the cell temperature through a measure of the temperature of its case. During this paper, tests were performed on all the cell cycles inside climatic chambers, for which thermostatic set-point temperature was always kept to $25^{\circ} \mathrm{C}$. This means that the results shown in this paper refer to cell temperatures over $25^{\circ} \mathrm{C}$. It is herein useful to anticipate that the maximum cell measured temperature increase will be of around $35^{\circ} \mathrm{C}$, recorded for cell500, letting the cell reach a temperature around $60^{\circ} \mathrm{C}$. Hence, the paper findings will correlate the cell aging indicators to cell temperatures between $25^{\circ} \mathrm{C}$ and around $60^{\circ} \mathrm{C}$. This range is the typical temperature window at which lithium batteries typically operate, both in vehicular and stationary applications.

Tests such as the ones of this paper, inside lower temperature chambers, would produce information on the indicators when the cell is at a lower temperature, which might be useful in certain circumstances.

Repeating our tests at different room temperatures is therefore an interesting possibility, even though aging tests are very long and costly, and therefore their design and schedule must be carefully evaluated in terms of cost/benefit ratio.

It is noticeable that paper [12] discusses results similar to this paper's, but at lower room temperatures.

\subsection{End-of-Discharge Voltage}

Another indicator potentially useful to understand the cell degradation effect is the cell voltage $V_{\mathrm{EOD}}$ reached at the end of each discharging step during the cycling periods. When it goes below the allowed threshold value of $2.65 \mathrm{~V}$, the cell is said to have reached its end of life. For this reason, in this paper, we use a definition of the state-of-life (SOL) of each cell based on the level of their end-of-discharge voltage. In this way, we can analytically define the SOL by the application of Equation (2), where $V_{E O D}^{B O L}$ is the end-of-discharge voltage and is the very first $V_{\mathrm{EOD}}$ measured (at the beginning of life), and the $V_{t h}$ is the minimum voltage threshold allowed (i.e., $2.65 \mathrm{~V}$ ).

$$
S O L=\frac{V_{E O D}-V_{t h}}{V_{E O D}^{B O L}-V_{t h}}
$$




\subsection{Internal Resistance}

The internal resistance of lithium cells is one of the parameters that are more commonly found in the literature as an aging indicator [13-16]. This is because the most known aging phenomena, the thickening of the solid electrolyte interphase (SEI), can be directly correlated to rises in the physical ohmic behavior of the cells $[17,18]$. However, it is questionable as to what exactly the internal resistance is; the best way is to define it through a measurement procedure. Generally, the application of a current step is considered, as per ISO 12405-4:2018 and IEC 62660-1:2010 [19] and the representation in Figure 3.

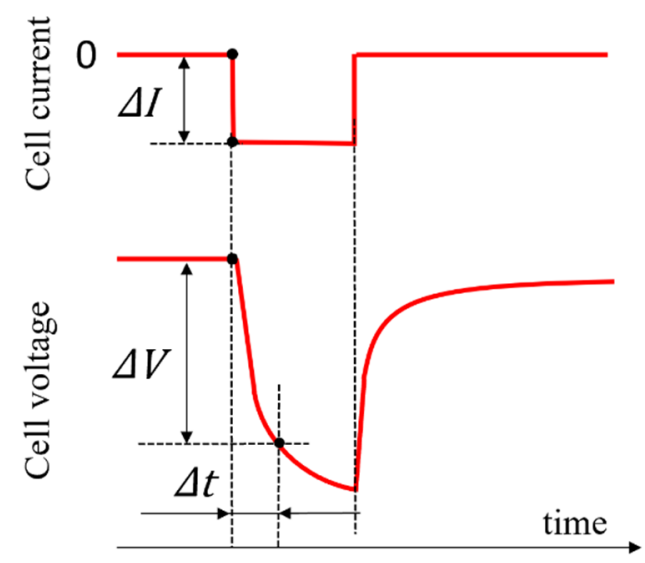

Figure 3. Current voltage step test for cell internal resistance identification.

The steps in the current shape are shown here to have vertical fronts; in actual tests, the fronts are not exactly vertical, but are acceptable as soon as their durations are much lower than the lowest value considered for $\Delta t$. The cell internal resistance $R_{\text {int }}$ is calculated as the ratio between the cell voltage variation $(\Delta V)$ and current variation $(\Delta I)$ :

$$
R_{\text {int }}=\frac{\Delta V}{\Delta I}
$$

while the definition (3) must be complemented with the indication of the time interval $(\Delta t)$ between the two voltage current samples taken.

Depending on how long this interval into the pulse of Equation (3) takes to be calculated, different physical phenomena occur; moving from a small-time interval to a larger one, three main resistances associated to the cell internal phenomena can be measured $[17,20,21]$. The first one is the pure ohmic cell response, often indicated by $R_{0}$, which comprises the whole electronic resistance, as well as the bulk electrolyte ionic resistance of the cell. Ideally, the $R_{0}$ calculation is the result of the application of Equation (3) with $\Delta t$ tending to zero. Using a larger time interval, say $4-5 \mathrm{~s}$, the very same ratio between $\Delta V$ and $\Delta I$ produces the calculation of the charge transfer resistance $\left(R_{\mathrm{CT}}\right)$, which is attributed to a charge transfer reaction at the electrode/electrolyte interface. Finally, choosing an even larger time interval, in the order of $10 \mathrm{~s}$, it is possible to evaluate the polarization cell resistance $\left(R_{\mathrm{P}}\right)$, which accounts for ionic diffusion in the solid phase.

Separating all these phenomena is not an easy task, especially because the borders between the three aspects are not easily detected as they change as a function of the type of lithium cell, the cell size, state of charge, and temperature. For these reasons, in this study, we applied the very same approach of Equation (3) by evaluating the cell internal resistance as a function of the number of cycles performed, by adopting three different time intervals for each cell. The purpose is to find out if any of the time intervals chosen can outline a cell internal resistance that can be easily correlated to the cell aging level. Under this light, it will be also possible to discuss which kind of the three resistance cell phenomena can be associated to the cell degradation. 
Our study was performed in correspondence with either a discharging or charging step, as well as at different states of charge. Inside the cycling period profile adopted, we used two current steps: one where the current moves from zero to a rather constant discharge value corresponding to the considered constant power (called start-of-discharge), and another where the current moves from the end-of-discharge value to the start-of-charge one (called end-of-discharge). The first step provides an indication of the internal resistance for nearly full cells, the second one of the internal resistance at the end-of-discharge, even though when using the larger powers, we discharged less than that of the lower.

\section{Results}

Table 2 shows some global parameters resulting from our cycle tests. The depth of discharge (DOD) was calculated according to (4), where $t_{0}$ and $t_{1}$ are the initial and the final times of the cycle discharge, respectively (Figure 1 ), and $C_{n}$ is the nominal cell capacity. Average discharge currents were calculated at the beginning (cycle \#10) and the end (cycle \#4950, \#1060, \#430) of the cell life.

Table 2. Some global parameters of the cycle-life tests.

\begin{tabular}{ccccc}
\hline Cell under Test & Test Power (W) & DOD (\%) & \multicolumn{2}{c}{ Average Discharge Current (A) } \\
\hline Cell250 & \multirow{2}{*}{250} & 33 & Cycle \#10 & Cycle \#4950 \\
& & & 78.0 & 84.9 \\
Cell375 & \multirow{2}{*}{375} & 50 & Cycle \#10 & Cycle \#1060 \\
& & & 118.1 & 124.9 \\
Cell500 & \multirow{2}{*}{500} & 70 & Cycle \#10 & Cycle \#430 \\
& & & 161.0 & 167.0 \\
\hline
\end{tabular}

The three cells were tested according to powers that follow a linear progression. This reflected in a similar progression of the cell current, because of the very flat voltage trend of LFP cells. The shown average value of the discharging current indicated a very modest increase due to the reduction of the average discharge voltage as soon as the cell became old. Because the cycle patterns were unchanged between the cells and the duration of the cycling discharging steps was always the same, the different DODs also showed a nearly linear decrease with the charge/discharge power.

$$
D O D=\int_{t_{0}}^{t_{1}} \frac{i(t)}{C_{n}} d t
$$

\subsection{Aging Indicators}

\subsubsection{Available Capacity}

Figure 4 shows the available capacity measured during the cell characterization phases, as a function of the number of cycles performed, for each cell under study. The capacity of each cell was normalized to the beginning of life value by the application of Equation (1).

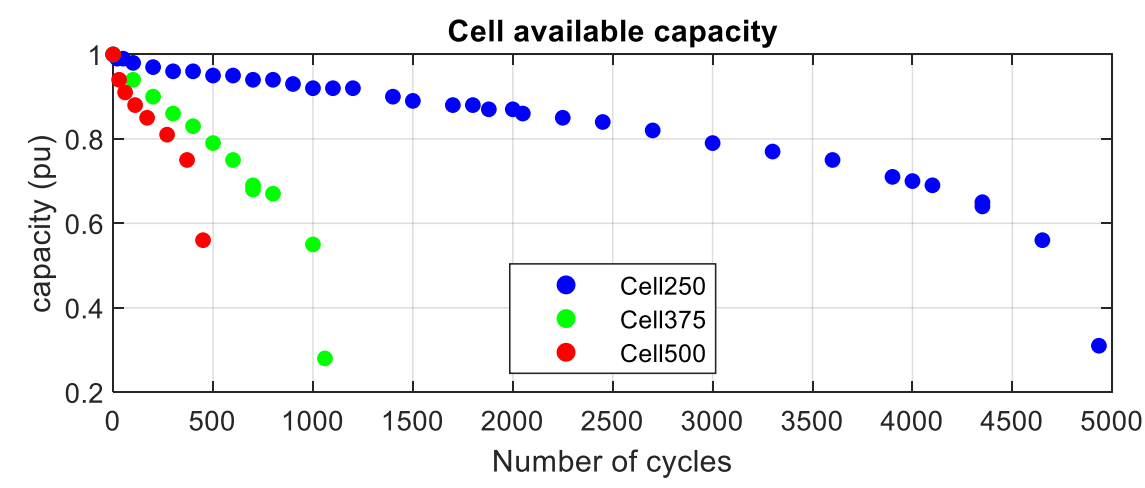

Figure 4. Cell capacity as a function of the number of cycles performed. 
Considering that each cycle implies the delivery of a known amount of energy, we have summarized the following data in Table 3.

Table 3. Lifetime delivered energies.

\begin{tabular}{ccc}
\hline Test Power (W) & Number of Cycles Performed & Lifetime Energy (kWh) \\
\hline 500 & 430 & 53.8 \\
375 & 1060 & 100.3 \\
250 & 4950 & 309.4 \\
\hline
\end{tabular}

As expected, the lifetime delivered energy increased dramatically as the power lowered. The data in the table suggest that power levels below $300 \mathrm{~W}$ may be considered for a real-life application in a recharging station. As discussed in Section 3.1, the available capacity is a rather obvious aging indicator, although very unpractical since it requires performing ad hoc discharges to get its value. However, the plots in Figure 4 are useful to obtain information of the shape of these curves over the cycle numbers, showing that the behavior was approximately linear up to roughly $80 \%$ of the cell total cycle life.

\subsubsection{End-of-Discharge (EOD) Voltage and Heat Generation}

The EOD voltage could in principle be much more practical in evaluating the cell's SOL, since the discharge profile is programmed to be very much the same in nearly all the discharges. Moreover, the EOD voltage can be measured at the end of each $15 \mathrm{~min}$ power delivery, without the need of resorting to ad hoc tests to evaluate the SOL. Figure 5 shows the end-of-discharge voltages of all the cycles performed with the three cells.
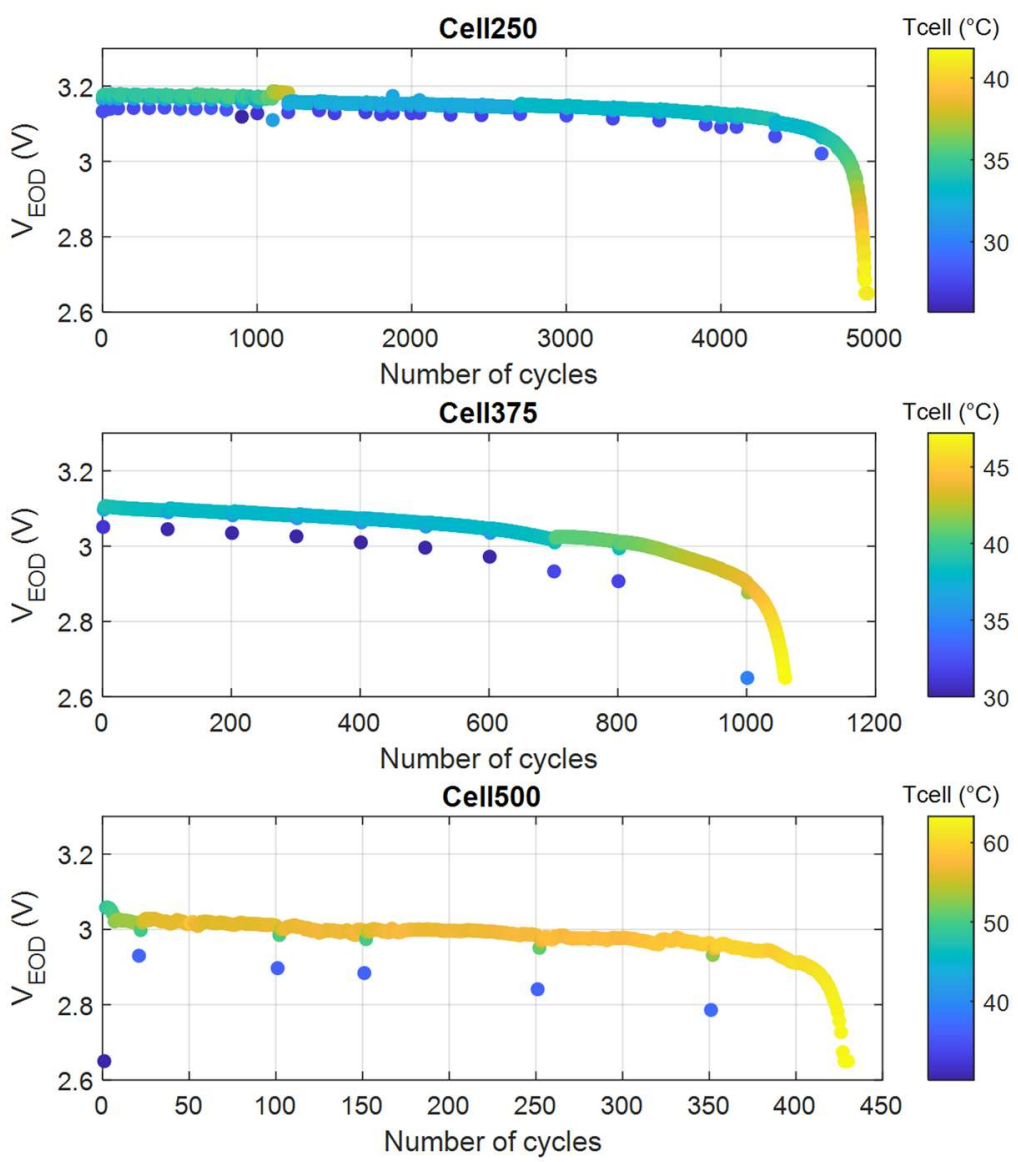

Figure 5. End-of-discharge voltage as a function of the number of cycles performed and of the cell case temperature. 
Each dot in the plots is also characterized by the cell's temperature since it was shown to have a substantial effect on this indicator. In fact, some of the discharges (namely, the first ones occurring after a CCP) happened to be performed at a lower temperature because every cycling period starts with the cells at room temperature, and it needs to take a few cycles before the thermal regime is reached. This causes the corresponding values to be out of the general curve trend (blue dots in the figure). It was also recommended that if we wanted to use the end-of-discharge voltage as an aging indicator, we must correlate it with the cell's temperature: the lower the temperature, the lower the voltage. Even though this was not searched during the experimental tests, it is a nice result: not only the plots in Figure 5 show the $V_{\mathrm{EOD}}$ trend when the cell was not in its regime temperature, but also its value at the lower temperature. We also note that at the end of life, the cell heat generation grew significantly. In fact, since the cell was still held in a thermostatic chamber, its higher temperature near the end-of-life indicated a larger heat generation. This fact agrees with the meaningful increase of the internal resistance of the cells in correspondence of the end-of-discharge experimentally measured (cf. Section 4.1.3). The results on $V_{\text {EOD }}$ showed additional interesting information obtained from zooming in on some of the curves in Figure 5. Consider, for instance, Figure 6.

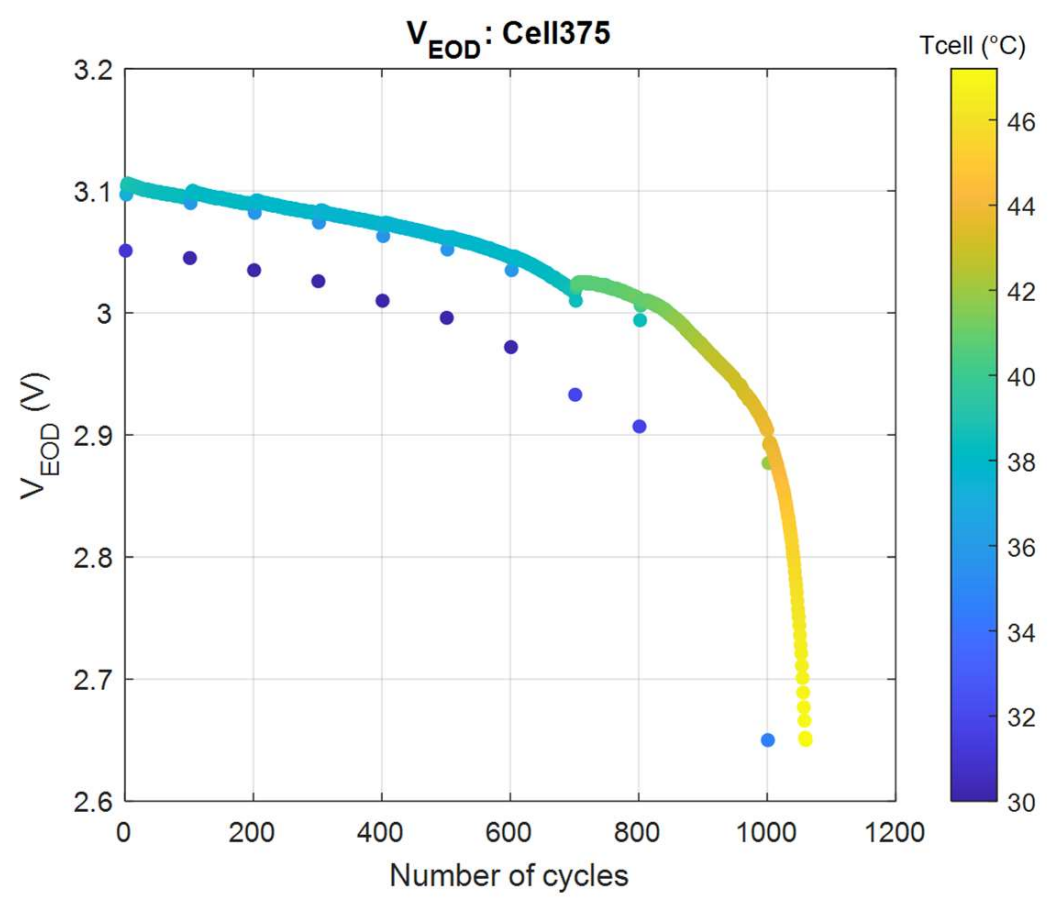

Figure 6. A zoom on one of the end-of-discharge voltages shown in Figure 5.

By observing this figure, it is possible to extract the end-of-dicharge voltage information at different temperature ranges. This is a consequence of the fact that the very first cycle after a CCP finds the cell much cooler (by $7-8^{\circ} \mathrm{C}$ ), and the second one slightly cooler than the others. In this figure, a CCP occurs at each 100 cycles for the first 800 cycles, and each 200 cycles after, until reaching the end-of-discharge threshold of $2.65 \mathrm{~V}$. Another interesting observation regarding this figure is that the rest time (a few hours) that occurred systematically between a CCP and the start of the subsquent cycling period had some effect on the cell's ability to deliver power. In fact, at the beginning of each cycling period, we observed a larger end-of-discharge voltage, which cannot be explained on the bases of the temperatures we measured. We can only hypothesize that the rest allowed charge diffusion inside the cell, which favours subsequent discharges. This is consistent with what we know about electrochemical cells, which, after rests, show an increased ability to deliver charge. Nevertheless, the most important observation we can have on the figures in this section regards the ability of $V_{\mathrm{EOD}}$ to perform as a SOL indicator. In this respect, we note that: 
- Throughout the entire cell cycle life, the end-of-discharge voltage is a good indicator of the cell's SOL, and for a given temperature, a linear interpolation may be used;

- At low SOLs (large cycle numbers), a significant temperature rise is a good indicator, in conjunction with a steep fall of VEOD of the imminent cell end-of-life.

In all cases, we note that the thermal chamber temperature was constantly held at $25^{\circ} \mathrm{C}$.

\subsubsection{Internal Resistance and Heat Generation}

The cell internal resistance we intended to measure was discussed in Section 3.4. By the application of Equation (3), we showed that the internal resistance value that we measure depends on the interval $\Delta t$, at which voltage and current samples are taken. It also depends on the battery SOC. Therefore, we herein analyze the internal resistance trend at the two SOC levels available for each cell under study: start-of-discharge and end-of-discharge, by using different values for $\Delta t$. It is here important to underline that the first SOC value is the same for every cell under study: i.e., SOC $=100 \%$, because the beginning of every discharge phase starts with the cells fully charged. Hence, the second value depends on each cell, since the corresponding DODs are different (see Table 2, i.e., SOC $=67 \%$ for cell 250 , SOC $=50 \%$ for cell 375 , and SOC $=30 \%$ for cell 500 ). Regarding $\Delta t$, we chose to evaluate Equation (3) using three different time intervals: short, medium, and large. Figure 7 shows the internal resistance evaluation of cell375, in the case of evaluation at $\mathrm{SOC}=100 \%$ (star-of-discharge). Since our cell tester did not allow for direct determination of $\Delta t$, we filtered out the intervals we obtained from measurement. The actual intervals used for computations were $0.01 \mathrm{~s} \leq \Delta t \leq 0.1 \mathrm{~s}$ for the upper plot in Figure $7,0.9 \mathrm{~s} \leq \Delta t \leq 1.1 \mathrm{~s}$ for the middle plot, and $9 \mathrm{~s} \leq \Delta t \leq 11 \mathrm{~s}$ for the bottom plot. From Figure 7, we can infer some points:

- The resistance evaluation must be paired with the cell case temperature. Because these values are taken immediately after a CCP, where, as already mentioned, the cell's temperature is lower, the corresponding resistances are significantly larger.

- There are some resistance changes after the cell has been rested without cycling. Indeed, during our tests, cell 375 was left inactive for a few months after cycle number 700 and a few days after the 1000th cycle. Correspondingly, we saw a deviation from the previous trends, apparently due to internal battery state changes, not captured by temperature alone. It is reasonable to assume that the inactive periods between cycling phases impact the cell behavior by increasing the availability to deliver power. - If we do not consider the extra points mentioned in the first bullet, the measured resistance over time had a rather constant behavior. Its trend over the entire cycle life displayed meaningful variation only if $\Delta t=10 \mathrm{~s}$ was used. However, the usage of this value was tricky, since some battery rests offsets the larger life-related $R_{\mathrm{i}}$ change, as discussed in the previous bullet point.

Incredibly different internal resistance experimental trends were displayed by the very same $R_{\mathrm{i}}$ evaluation but performed at every end of discharge, in correspondence of intermediate SOC levels and not for fully charged cells. The corresponding DODs are shown in Table 2, and SOC $=1-$ DOD. For this case, the internal resistances computed as $R_{i}=\Delta V / \Delta i$ with evaluation of deltas at different time intervals are shown in Figure 8, again for the case of cell375. The considered time intervals have exactly the same meaning as in Figure 7. 

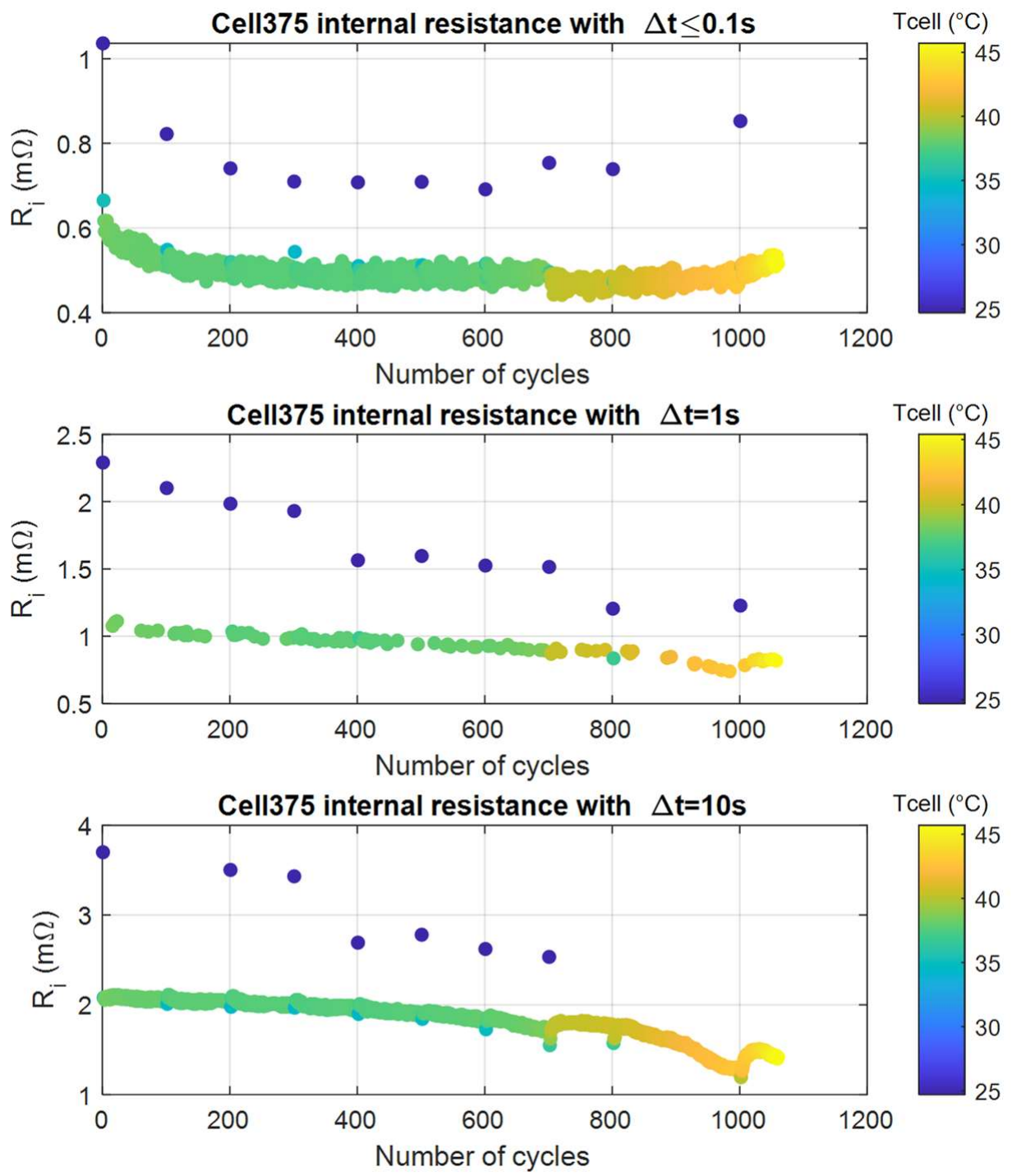

Figure 7. Trend of the start-of-discharge internal resistance for cell 375 at SOC $=100 \%$ as a function of the number of cycles and cell case temperature for different $\Delta t$ intervals.

Now we can make the following comments:

- The case with $\Delta t=0.1 \mathrm{~s}$ is rather useless. We had a cloud with resistances above $0.8 \mathrm{~m} \Omega$, which was probably due to some weakness of our data storing mechanism; moreover, we had some cool samples (blue dots) that were out of the bulk of the points. Even though we found an algorithm to take all these values out, the general trend of most of the points, the low curve, showed that the variation in resistance was not very large; moreover, rests in the battery operation (as we said the battery was at rest a few months at cycle number 700) caused significant changes in $\Delta t=0.1 \mathrm{~s}$ resistances.

- The cases with $\Delta t=1 \mathrm{~s}$ and $\Delta t=10 \mathrm{~s}$ instead showed useful results. As with all the previous cases, we must combine the Ri measure with temperature, since the trend with resistance values measured immediately after $\mathrm{CCP}$, where the cell was cooler, showed much larger resistances values (blue dots) than the others. Once we were able to select data that were thermally homogeneous (blue points discarded), we saw a significant variation of the internal resistance in function of the cell number of cycles, which was by far larger than the variation occurring due to cell resting, (e.g., after the cell rest at cycle number 700 . Between the first and the last internal resistance values, the increase was $43 \%$ for the case $\Delta t=1 \mathrm{~s}$ and $79 \%$ for the $\Delta t=10 \mathrm{~s}$. Therefore, the 
end-of-discharge resistance was a good indicator of the battery aging, especially when SOL was at least $60 \%$.
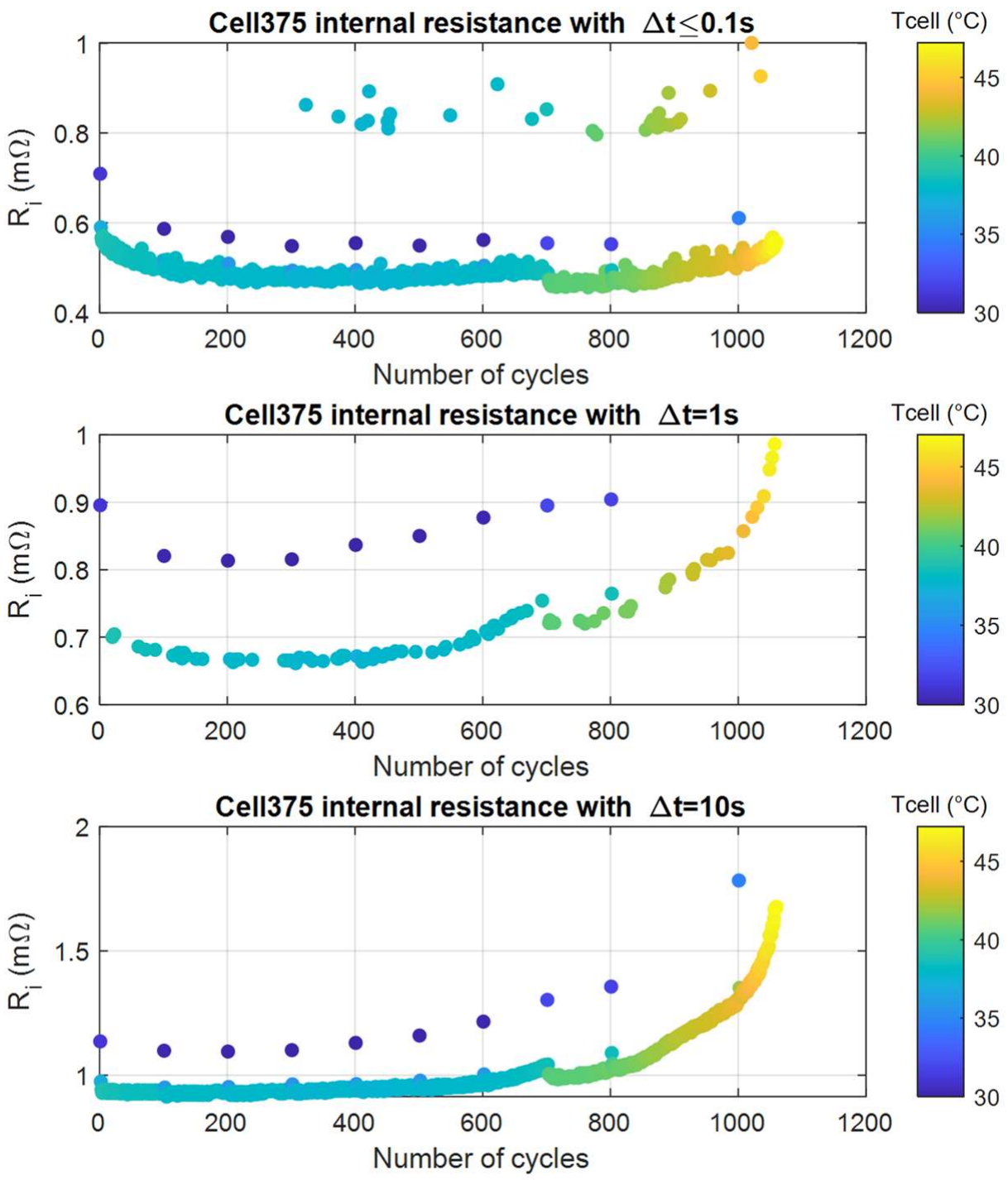

Figure 8. Trend of the start-of-discharge internal resistance for cell 375 at SOC $=50 \%$ as a function of the number of cycles and cell case temperature for different $\Delta t$ intervals.

Unfortunately, the situation was not as good for the other two cells, wherein the $\Delta t=0.1 \mathrm{~s}$ was useless (again, probably due to limitation of our measuring hardware). In Figure 9, we also report the internal resistance trends for the cell250 and cell500, in the case of $\Delta t$ equal to $1 \mathrm{~s}$ and $10 \mathrm{~s}$. The following observations were made:

- $\quad$ The cell250 value showed a significant change only starting from $88 \%$ SOL.

- The cell500 had less regular behavior and showed significant increase, for the best case with $\Delta t=10 \mathrm{~s}$, starting from around $80 \%$ SOL. 

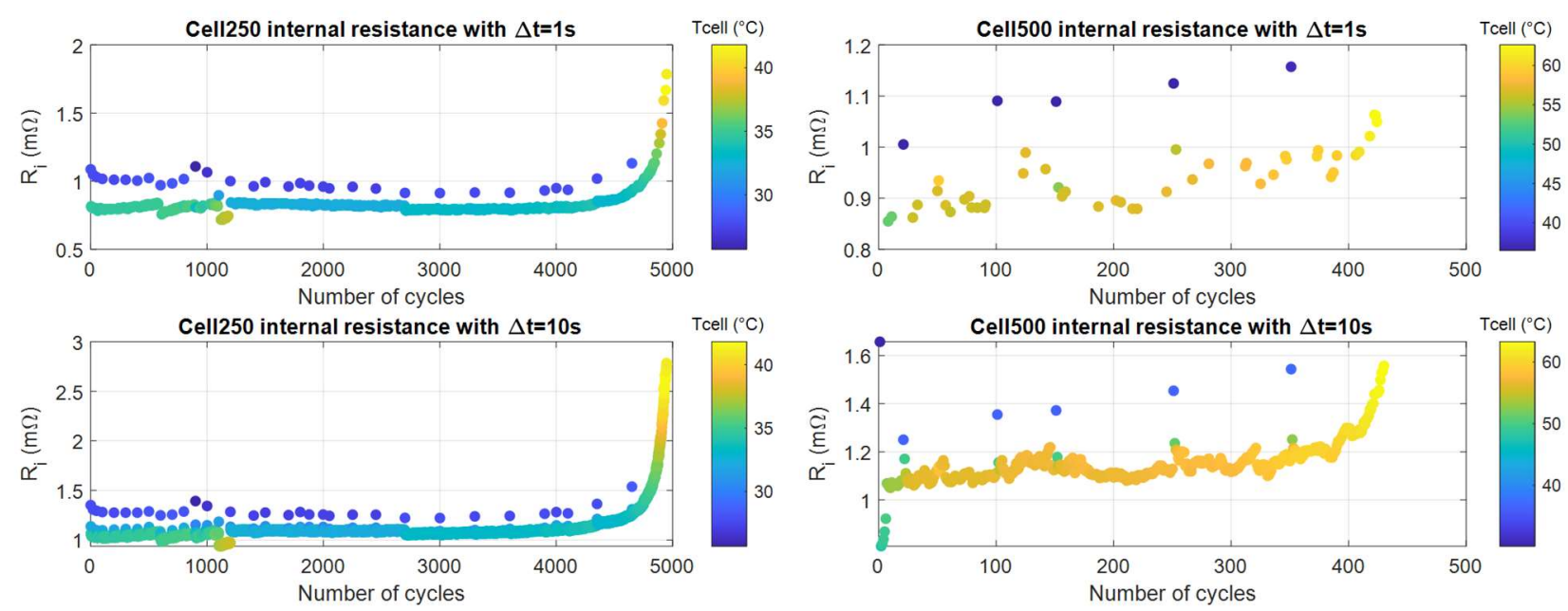

Figure 9. Trend of the end-of-discharge internal resistance as a function of the number of cycles and cell case temperature for different $\Delta t$ intervals, cell250 (left side) and cell500 (right side).

\section{Conclusions}

In this paper, specific aging tests were performed on three identical LFP cells located in the same ambient conditions, with the aim of evaluating their cycle-life and trying to find aging indicators, which could help predictive maintenance. The stress to which the cells were subjected was defined as a function of the application of these batteries, and it consisted in 15 min constant-power discharge and subsequent constant-power charge.

The results showed that the use of $500 \mathrm{~W}$ constant power was very stressful for the cells, and implied only 430 cycles, with a lifetime delivered energy of roughly $54 \mathrm{kWh}$. The $375 \mathrm{~W}$ and $250 \mathrm{~W}$ constant powers were more adequate and implied $100 \mathrm{kWh}$ and $310 \mathrm{kWh}$ lifetime delivered energy, respectively.

The tests showed that, in addition to the obvious deliverable charge when subject to constant-current discharge, useful aging indicators are the end-of-discharge voltage and the internal resistance, even though their evaluation must be carefully coupled with cell temperature measurements.

The paper has also shown some details on how to measure the internal resistance in order to let it be a reasonably useful SOL indicator. In particular, in order to better correlate the cell internal resistance evaluation to the cell actual aging level, intermediate SOC levels are to be preferred to a $100 \%$ SOC.

Author Contributions: Conceptualization, M.C.; methodology, M.C.; validation, C.S.; investigation, M.C. and C.S.; data curation, C.S.; writing—original draft preparation, C.S.; writing—review and editing, M.C., C.S., G.L. and D.P.; visualization, G.L. and D.P.; supervision, G.L. and M.C.; project administration, M.C.; funding acquisition, M.C. All authors have read and agreed to the published version of the manuscript.

Funding: The study presented in this paper was funded by Italian Regione Toscana for the SUMA (Struttura Multifunzionale Urbana Attiva) project, BANDO “FAR-FAS 2014"—CUP 4421. 02102014.07 20000220 and D51B18000740009.

Institutional Review Board Statement: Not applicable.

Informed Consent Statement: Not applicable.

Data Availability Statement: Data sharing not applicable.

Conflicts of Interest: The authors declare no conflict of interest. 


\section{Appendix A}

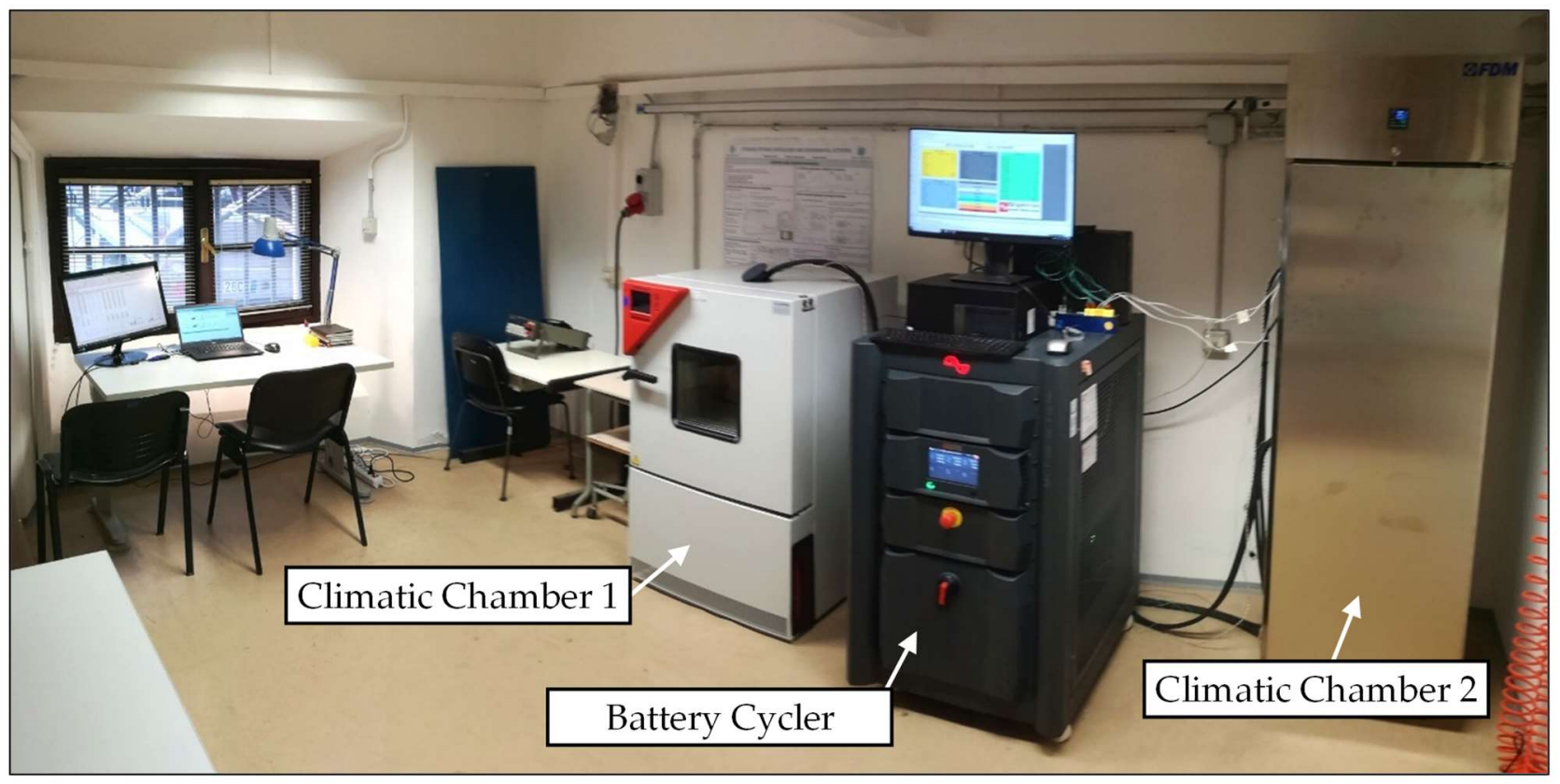

Figure A1. Battery laboratory of University of Pisa, DESTEC Department.

Table A1. Laboratory instrument specifics.

\begin{tabular}{|c|c|}
\hline \multicolumn{2}{|c|}{ Battery Cycler } \\
\hline Manufacturer & Digatron \\
\hline Voltage range $(\mathrm{V})$ & $0 \div 6$ \\
\hline Max current $(\mathrm{A})$ & 250 \\
\hline Voltage accuracy ( $\%$ of full scale) & 0.05 \\
\hline Current accuracy (\% of full scale) & 0.1 \\
\hline Min acquisition timestep (ms) & 10 \\
\hline \multicolumn{2}{|c|}{ Thermocouples } \\
\hline Type & “K” \\
\hline Expanded uncertainty $\left({ }^{\circ} \mathrm{C}\right)$ & $0.3(95 \%)$ \\
\hline \multicolumn{2}{|c|}{ Climatic Chamber 2} \\
\hline Manufacturer & Binder \\
\hline Temperature range $\left({ }^{\circ} \mathrm{C}\right)$ & $-40 \div+180$ \\
\hline Internal volume (L) & 53 \\
\hline Max set-point temperature oscillation $\left({ }^{\circ} \mathrm{C}\right)$ & \pm 0.3 \\
\hline \multicolumn{2}{|c|}{ Climatic Chamber 1} \\
\hline Manufacturer & FDM \\
\hline Temperature range $\left({ }^{\circ} \mathrm{C}\right)$ & $0 \div+70$ \\
\hline Internal volume $(\mathrm{L})$ & 370 \\
\hline Max set-point temperature oscillation $\left({ }^{\circ} \mathrm{C}\right)$ & \pm 0.5 \\
\hline
\end{tabular}

\section{References}

1. Batteries Europe Strategic Research Agenda for Batteries 2020 Report. Available online: https:/ / ec.europa.eu/energy/topics/ technology-and-innovation/batteries-europe/news-articles-and-publications/sra_en (accessed on 6 August 2021).

2. Warner, J. The Handbook of Lithium-Ion Battery Pack Design; Elsevier: Amsterdam, The Netherlands, 2015.

3. Wikner, E.; Thiringer, T. Extending Battery Lifetime by Avoiding High SOC. Appl. Sci. 2018, 8, 1825. [CrossRef]

4. Xu, B.; Oudalov, A.; Ulbig, A.; Andersson, G.; Kirschen, D.S. Modeling of Lithium-Ion Battery degradation for Cell Life Assessment. IEEE Trans. Smart Grid 2018, 9, 1131-1140. [CrossRef] 
5. Khalik, Z.; Bergveld, H.J.; Donkers, M.C.F. Ageing-Aware Charging of Lithium-Ion Batteries Using an Electrochemistry-Based Model with Capacity-Loss Side Reactions. In Proceedings of the American Control Conference (ACC), Denver, CO, USA, 1-3 July 2020; pp. 2213-2218.

6. Motapon, S.N.; Lachance, E.; Dessaint, L.A.; Al-Haddad, K. A generic cycle life model for lithium batteries based on fatigue theory and equivalent cycle counting. IEEE Open J. Ind. Electron. Soc. 2020, 1, 207-217. [CrossRef]

7. SUMA Project. Available online: https://www.destec.unipi.it/ricerca/progetti-nazionali-ed-internazionali/far-fas-2014/568 -progetto-suma (accessed on 4 May 2021).

8. Ceraolo, M.; Lutzemberger, G.; Poli, D.; Scarpelli, C. Experimental analysis of LFP lithium cells aging. In Proceedings of the IEEE International Conference on Environment and Electrical Engineering and 2020 IEEE Industrial and Commercial Power Systems Europe (EEEIC/I\&CPS Europe), Madrid, Spain, 9-12 June 2020; pp. 1-6.

9. Digatron Official Site. Available online: https://www.digatron.com/en-us/Solutions/Battery-Laboratory (accessed on 4 May 2021).

10. Binder Official Site. Available online: https:/ /www.binder-world.com/it (accessed on 4 May 2021).

11. Winston Batteries Official Site. Available online: http:/ / en.winston-battery.com/ (accessed on 4 May 2021).

12. Jaguemont, J.; Boulon, L.; Venet, P.; Dubé, Y.; Sari, A. Low temperature aging tests for lithium-ion batteries. In Proceedings of the IEEE 24th International Symposium on Industrial Electronics (ISIE), Rio de Janeiro, Brazil, 3-5 June 2015; pp. $1284-1289$.

13. Lee, H.; Park, J.; Kim, J. Comparative analysis of the $\mathrm{SOH}$ estimation based on various resistance parameters for $\mathrm{LiCoO}_{2}$ cells. In Proceedings of the IEEE Transportation Electrification Conference and Expo, Asia-Pacific (ITEC Asia-Pacific), Busan, Korea, 1-4 June 2016; pp. 788-792.

14. Jarraya, I.; Loukil, J.; Masmoudi, F.; Chabchoub, M.H.; Trabelsi, H. Modeling and Parameters Estimation for Lithium-Ion Cells in Electric Drive Vehicle. In Proceedings of the 15th International Multi-Conference on Systems, Signals \& Devices (SSD), Hammamet, Tunisia, 19-22 March 2018; pp. 1128-1132.

15. Gurjer, L.; Chaudhary, P.; Verma, H.K. Detailed Modelling Procedure for Lithium-ion Battery Using Thevenin Equivalent. In Proceedings of the IEEE International Conference on Electrical, Computer and Communication Technologies (ICECCT), Coimbatore, India, 20-22 February 2019; pp. 1-6.

16. Tan, X.; Tan, Y.; Zhan, D.; Yu, Z.; Fan, Y.; Qiu, J.; Li, J. Real-Time State-of-Health Estimation of Lithium-Ion Batteries Based on the Equivalent Internal Resistance. IEEE Access 2020, 8, 56811-56822. [CrossRef]

17. Mathew, M.; Janhunen, S.; Rashid, M.; Long, F.; Fowler, M. Comparative Analysis of Lithium-Ion Battery Resistance Estimation Techniques for Battery Management Systems. Energies 2018, 11, 1490. [CrossRef]

18. Barré, A.; Deguilhem, B.; Grolleau, S.; Gérard, M.; Suard, F.; Riu, D. A review on lithium-ion battery ageing mechanisms and estimations for automotive applications. J. Power Sources 2013, 2013, 680-689. [CrossRef]

19. Ruiz, V. Standard for the Performance and Durability Assessment of Electric Vehicles Batteries; JRC Technical Reports; European Commission: Brussels, Belgium, 2018.

20. Barai, A.; Uddin, K.; Widanage, W.D.; McGordon, A.; Jennings, P. A study of the influence of measurement timescale on internal resistance characterisation methodologies for lithium-ion cells. Sci. Rep. 2018, 8, 21. [CrossRef] [PubMed]

21. Kim, J.H.; Lee, S.J.; Lee, J.M.; Cho, B.H. A New Direct Current Internal Resistance and State of Charge Relationship for the Li-Ion Battery Pulse Power Estimation. In Proceedings of the IEEE International Conference on Power Electronics, Daegu, Korea, 22-26 October 2007; p. 1173. 